\title{
Prognostic Significance of Sarcopenia and Systemic Inflammatory Response in Patients With Esophageal Cancer
}

\author{
TOMOYUKI MATSUNAGA ${ }^{1}$, HIROSHI MIYATA ${ }^{1}$, KEIJIRO SUGIMURA ${ }^{1}$, MASAAKI MOTOORI ${ }^{2}$, \\ KEI ASUKAI ${ }^{1}$, YOSHITOMO YANAGIMOTO ${ }^{1}$, YUSUKE TAKAHASHI $^{1}$, AKIRA TOMOKUNI $^{1}$, \\ KAZUYOSHI YAMAMOTO ${ }^{1}$, HIROFUMI AKITA ${ }^{1}$, JUNICHI NISHIMURA ${ }^{1}$, HIROSHI WADA $^{1}$, \\ HIDENORI TAKAHASHI ${ }^{1}$, MASAYOSHI YASUI ${ }^{1}$, TAKESHI OMORI ${ }^{1}$, MASAYUKI OUE $^{1}$ and MASAHIKO YANO ${ }^{1}$ \\ ${ }^{1}$ Department of Gastroenterological Surgery, Osaka International Cancer Institute, Osaka, Japan; \\ ${ }^{2}$ Department of Surgery, Osaka General Medical Center, Osaka, Japan
}

\begin{abstract}
Background/Aim: The association between the presence of sarcopenia and systemic inflammatory response is unclear in patients with esophageal cancer. This study was performed to investigate the relationship between sarcopenia and systemic inflammatory response and clarify the effect of these factors on the prognosis in patients with esophageal cancer. Patients and Methods: This study included 163 patients with esophageal cancer. The patients' body composition was assessed before esophagectomy using multifrequency bioelectrical impedance. The relationship between sarcopenia and inflammatory factors were investigated before surgery. Results: Sarcopenia was significantly associated with a high $C$-reactive protein-to-albumin $(C R P / A l b)$ ratio $(p=0.046)$. Patients with sarcopenia significantly associated with worse overall survival $(O S)(p=0.025)$ and tended to show a worse recurrence-free survival $(R F S)(p=0.065)$. A high $C R P / A l b$ ratio was significantly associated with worse OS and RFS. Multivariate analysis revealed that among all inflammatory factors, only a high CRP/Alb ratio was an independent prognostic factor for RFS ( $p=0.022)$. Conclusion: Sarcopenia is associated with systemic inflammatory response such as high $C R P / A l b$ ratio, while the latter is an independent prognostic marker in patients with esophageal cancer.
\end{abstract}

Esophageal cancer is a highly aggressive malignant disease and has a high metastatic potential (1). Despite the development of multimodal therapies such as surgery, chemotherapy, and chemoradiation therapy, postoperative

Correspondence to: Hiroshi Miyata, Department of Gastroenterological Surgery, Osaka International Cancer Institute, 3-1-69 Otemae, Chuouku, Osaka 541-8567, Japan. Tel: +81 669451181, Fax: +81 669451885 e-mail: miyata-hi@mc.pref.osaka.jp

Key Words: Esophageal cancer, sarcopenia, C-reactive protein-toalbumin ratio. recurrence is observed in more than half of patients who have undergone transthoracic esophagectomy, and the prognosis of patients with esophageal cancer remains poor (2-4). In addition to various clinicopathological factors and the tumor stage, some other prognostic indicators have been discovered in previous studies of esophageal cancer because of the poor prognosis (5-7). Inflammatory factors are reportedly prognostic factors of cancer, and the close correlation between cancer and inflammation was first discovered by Virchow in 1863 (8). Many inflammatory markers that can be used to predict prognosis have been reported, such as the $\mathrm{C}$-reactive protein (CRP)-to-albumin ratio (CRP/Alb ratio), modified Glasgow prognostic score (mGPS), neutrophil-to-lymphocyte ratio (NLR), and platelet-to-lymphocyte ratio (PLR). These markers reportedly associated with the prognosis of various types of cancer, including esophageal cancer (9-14).

Sarcopenia, which is characterized by loss of skeletal muscle mass (SMM), has been mainly studied in older people and is known to impair physical performance and survival in this population (15-17). Sarcopenia has recently received great attention in the oncology field and is recognized as an important factor in predicting long-term prognosis in patients undergoing surgery for various types of cancer (18-21). The reason for the relationship between sarcopenia and poor cancer prognosis remains unclear, but inflammation may play a role (22). Previous evidence has supported the association of the systemic inflammatory response with sarcopenia. More specifically, proinflammatory cytokines, including interleukin-1 (IL-1), IL-6, and tumor necrosis factor- $\alpha$ (TNF- $\alpha$ ), were found to be mediators of anorexia and skeletal muscle proteolysis, the key components of cancer cachexia $(23,24)$. Proinflammatory cytokines and growth factors are released as part of the systemic inflammatory response to tumors and have profound catabolic effects on host metabolism, leading to muscle breakdown (25). This inflammatory cycle can, in turn, enhance tumor aggressiveness or reduce treatment response, impairing the transition into survivorship $(26,27)$. 
To the best of our knowledge, this is the first study to investigate the association between sarcopenia and systemic inflammatory markers and clarify the effect of these factors on the prognosis in patients with esophageal cancer.

\section{Patients and Methods}

Patients and perioperative treatment. From January 2013 to December 2015, 191 consecutive patients with thoracic esophageal cancer underwent esophagectomy with radical lymph node dissection at the Osaka International Cancer Institute in Japan. Among them, 21 patients did not undergo a preoperative assessment of body composition and 7 underwent noncurative esophagectomy. After excluding these 28 patients, 163 patients were enrolled in this study. Ninety-five patients were treated with neoadjuvant chemotherapy and 11 were treated with neoadjuvant chemoradiotherapy.

Our treatment strategy for esophageal cancer was as follows: patients with $\geq \mathrm{T} 2$, non-T4, or node-positive tumors (Stage $\geq 1 \mathrm{~B}$ ) received neoadjuvant chemotherapy followed by esophagectomy, and patients with $\mathrm{T} 4$ tumors suspected to have invaded other organs (T4b) received neoadjuvant chemoradiation therapy. Tumor staging was based on the 7th edition of the Union for International Cancer Control TNM staging system (28).

Patients were carefully followed up from the initial treatment until March 2018. Physical examinations and blood tests were performed every 3 months after discharge from the hospital. Abdominal ultrasonography and/or computed tomography were performed at least every 6 months to check for recurrence.

Definition of inflammation-based factors. The nutrition- and inflammation- based prognostic scores used in this study were: the $\mathrm{CRP} / \mathrm{Alb}$ ratio (CRP measured in $\mathrm{mg} / \mathrm{l}$ and albumin measured in $\mathrm{g} / \mathrm{l}$ (29)); the mGPS, which was a combination of CRP and albumin (patients with a normal albumin level $(\geq 3.5 \mathrm{~g} / \mathrm{l})$ and normal CRP level $(\leq 10 \mathrm{mg} / \mathrm{l})$ were allocated a score of 0 , patients with an elevated CRP level ( $>10 \mathrm{mg} / \mathrm{l})$ were allocated a score of 1 , and patients with both a low albumin level $(<3.5 \mathrm{~g} / \mathrm{l})$ and elevated CRP level (>10 mg/l) were allocated a score of $2(30))$; the NLR (13); the PLR (31); and the prognostic nutritional index (PNI), which was calculated by the formula $10 \times$ albumin $(\mathrm{g} / \mathrm{dl})+0.005 \times$ lymphocyte count/ $\mu 1$ (32). All indicators involved in the calculation of the nutrition- and inflammation-based prognostic scores were evaluated preoperatively.

The Youden index was calculated using the receiver operating characteristic (ROC) curve to determine an optimal cut-off value for the recurrent status of esophageal cancer in association with each inflammatory factor (CRP/Alb ratio, NLR, PNI, and PLR).

Assessment of body composition. Body composition was assessed before esophagectomy using multifrequency bioelectrical impedance with eight electrodes (InBody 720; Biospace, Tokyo, Japan). Various parameters of body composition (SMM, body weight, and body mass index) were automatically measured by the InBody 720 . The normal range of SMM in each patient was shown by the InBody 720 and ranged from $90 \%$ to $110 \%$ of the standard SMM, which was calculated according to the age, sex, and height of each patient. In this study, sarcopenia was defined as an SMM below the lower limit of the standard SMM $(<90 \%$ of the standard) $(33,34)$.
Statistical analysis. Continuous variables are expressed as mean \pm standard deviation. The $\chi^{2}$ test or Fisher's exact test was used to compare categorical variables. Student's $t$-test was used to compare continuous variables. The Mann-Whitney $U$-test was used to compare sequential variables. The Wilcoxon test was used to compare continuous variables. Survival curves were calculated using the Kaplan-Meier method, and differences between survival curves were examined with the log-rank test. Cox regression was used for univariate and multivariate analyses. The hazard ratio (HR) and $95 \%$ confidence interval (CI) were computed with the Cox proportional hazards model. We used univariate and multivariate analyses of factors considered prognostic for recurrence-free survival (RFS). All calculations were performed using the JMP v9.0.1 software (SAS Institute, Inc., Cary, NC, USA), and $p$-values of $<0.05$ were considered significant.

\section{Results}

Clinical features of patients. The clinicopathological characteristics of patients with and without sarcopenia are shown in Table I. The sarcopenia group comprised 82 patients $(50.3 \%)$, and the non-sarcopenia group comprised 81 patients $(49.7 \%)$. The body mass index and SMM were significantly lower in patients with sarcopenia than without $(p<0.001)$. However, no significant differences were observed in age, sex, smoking, tumor location, neoadjuvant therapy, histology, depth of tumor invasion, lymph node metastasis, pathological stage, or incidence of complication between the two groups.

Inflammatory factors related to sarcopenia. The association of sarcopenia with various measures of the systemic inflammatory response in patients with esophageal cancer is shown in Table II. Receiver operating characteristic analysis revealed the optimal cut-off value of each inflammatory factor (CRP/Alb ratio, NLR, PNI, and PLR) (Table III). A high $\mathrm{CRP} / \mathrm{Alb}$ ratio $(\geq 0.00375)$ was significantly more frequent in the sarcopenia than non-sarcopenia group $(p=0.046)$. Furthermore, the mGPS was significantly higher in the sarcopenia group $(p=0.041)$. The platelet count was also significantly higher in the sarcopenia group $(p=0.016)$. However, no significant differences were observed between the two groups regarding the white blood cell, neutrophil, or lymphocyte counts, albumin, CRP, PNI, NLR, or PLR.

Relationship of sarcopenia and inflammatory factors with long-term prognosis. In this study, 37 patients died of esophageal cancer recurrence, and 3 patients died of other diseases (pneumonia, $n=2$; multiple organ failure after a traffic accident, $n=1$ ). The overall survival (OS) rate was significantly poorer in patients with sarcopenia than in those without (2-year survival rate, $73.1 \%$ vs. $85.1 \%$, respectively; $p=0.025$ ) (Figure 1A). The RFS rate tended to be poorer in patients with than without sarcopenia (2-year RFS, $62.8 \%$ vs. $76.3 \%$, respectively; $p=0.065$ ) (Figure 1B). 
Table I. Clinical features of esophageal cancer patients with and without sarcopenia

\begin{tabular}{|c|c|c|c|c|}
\hline & $\begin{array}{l}\text { Total patients } \\
\quad(\mathrm{n}=163)\end{array}$ & $\begin{array}{l}\text { Patients with sarcopenia } \\
\qquad(\mathrm{n}=82)\end{array}$ & $\begin{array}{l}\text { Patients without sarcopenia } \\
\qquad(\mathrm{n}=81)\end{array}$ & $p$-Value \\
\hline Age, years ${ }^{a}$ & $64.7 \pm 8.0$ & $66.2 \pm 7.2$ & $63.7 \pm 8.8$ & 0.132 \\
\hline Gender $^{b}$ & & & & 1.000 \\
\hline Male & $128(79)$ & $64(78)$ & $64(79)$ & \\
\hline Female & $35(21)$ & $18(22)$ & $17(21)$ & \\
\hline $\mathrm{BMI}^{\mathrm{a}}\left(\mathrm{kg} / \mathrm{m}^{2}\right)$ & $21.6 \pm 3.3$ & $19.6 \pm 2.2$ & $23.5 \pm 3.1$ & $<0.001$ \\
\hline SMMa & $24.4 \pm 4.6$ & $22.2 \pm 3.3$ & $26.6 \pm 4.6$ & $<0.001$ \\
\hline Brinkman index ${ }^{a}$ & $716 \pm 612$ & $758 \pm 512$ & $683 \pm 660$ & 0.063 \\
\hline Smoking ${ }^{b}$ & & & & 0.534 \\
\hline Present & $139(85)$ & $71(87)$ & $68(84)$ & \\
\hline Absent & $24(15)$ & $11(13)$ & $13(16)$ & \\
\hline Tumor location ${ }^{b}$ & & & & 0.341 \\
\hline Upper & $32(20)$ & $16(19)$ & $16(20)$ & \\
\hline Middle & $86(53)$ & $49(60)$ & $37(46)$ & \\
\hline Lower & $45(27)$ & $18(21)$ & $27(34)$ & \\
\hline Neoadjuvant therapy ${ }^{b}$ & & & & 0.635 \\
\hline None & $57(35)$ & $28(34)$ & $29(36)$ & \\
\hline Chemotherapy & $95(58)$ & $46(56)$ & $49(60)$ & \\
\hline Chemoradiotherapy & $11(7)$ & $8(10)$ & $3(4)$ & \\
\hline Histology & & & & 0.535 \\
\hline Squamous cell carcinoma & $154(95)$ & $76(93)$ & $78(96)$ & \\
\hline Adenocarcinoma & $9(5)$ & $6(7)$ & $3(4)$ & \\
\hline Lymphadenectomyb & & & & 0.177 \\
\hline Two fields & $50(31)$ & $21(26)$ & $29(36)$ & \\
\hline Three fields & $113(69)$ & $61(74)$ & $52(64)$ & \\
\hline Depth of tumor invasion ${ }^{b}$ & & & & 0.563 \\
\hline T0 & $22(13)$ & $10(12)$ & $12(15)$ & \\
\hline $\mathrm{T} 1$ & $58(36)$ & $30(37)$ & $28(34)$ & \\
\hline $\mathrm{T} 2$ & $21(13)$ & $8(10)$ & $13(16)$ & \\
\hline $\mathrm{T} 3$ & $60(37)$ & $33(40)$ & $27(34)$ & \\
\hline $\mathrm{T} 4$ & $2(1)$ & $1(1)$ & $1(1)$ & \\
\hline Lymph node metastasis ${ }^{b}$ & & & & 0.270 \\
\hline No & $71(44)$ & $30(37)$ & $41(51)$ & \\
\hline N1 & $59(3)$ & $37(45)$ & $22(27)$ & \\
\hline $\mathrm{N} 2$ & $17(10)$ & $7(8)$ & $10(12)$ & \\
\hline N3 & $16(10)$ & $8(10)$ & $8(10)$ & \\
\hline Pathological stage ${ }^{b}$ & & & & 0.175 \\
\hline 0 & $12(7)$ & $4(5)$ & $8(10)$ & \\
\hline $\mathrm{I}$ & $48(29)$ & $21(26)$ & $27(33)$ & \\
\hline II & $45(28)$ & $26(32)$ & $19(23)$ & \\
\hline III & $54(33)$ & $29(35)$ & $25(31)$ & \\
\hline IV & $4(3)$ & $2(2)$ & $2(3)$ & \\
\hline \multicolumn{5}{|l|}{ Postoperative complications $\mathrm{b}$} \\
\hline Pneumonia & $19(11.7)$ & $11(13.4)$ & $8(9.9)$ & 0.480 \\
\hline Anastomotic leakage & $9(5.5)$ & $5(6.1)$ & $4(4.9)$ & 0.751 \\
\hline
\end{tabular}

a Data are presented as mean \pm standard deviation. ${ }^{b}$ Data are presented as n (\%). BMI, Body mass index; SMM, skeletal muscle mass

OS and RFS rates were significantly poorer in patients with a high than low CRP/Alb ratio $(p<0.001$ and $p<0.001$, respectively) (Figure $1 \mathrm{C}, \mathrm{D})$. OS was significantly poorer in patients with a mGPS of 1 or 2 , compared to those with a mGPS of 0 (2-year survival rate, $75.5 \%$ vs. $85.2 \%$, respectively; $p=0.049$ ) (Figure $2 \mathrm{~A}$ ), and the same tendency was observed in the RFS rate, although it was not significant $(p=0.073)$ (Figure 2B). OS and RFS rates were significantly poorer in patients with a high than in those with a low NLR $(p<0.001$ and $p=0.003$, respectively) (Figure 2C, D). However, other inflammatory markers such as the PNI and PLR were not associated with prognosis (Figure 3A-D).

Factors related to prognosis. The association of the preoperative clinicopathological parameters, including inflammatory factors, with the RFS after esophagectomy for 
Table II. Relationships between sarcopenia and measures of systemic inflammatory response in patients with esophageal cancer.

\begin{tabular}{|c|c|c|c|c|}
\hline & $\begin{array}{l}\text { Total patients } \\
\quad(\mathrm{n}=163)\end{array}$ & $\begin{array}{l}\text { Patients with sarcopenia } \\
\qquad(\mathrm{n}=82)\end{array}$ & $\begin{array}{l}\text { Patients without sarcopenia } \\
\qquad(\mathrm{n}=81)\end{array}$ & $p$-Value \\
\hline $\mathrm{WBCs}^{\mathrm{a}}$ & $5757 \pm 1813$ & $5939 \pm 1868$ & $5719 \pm 1902$ & 0.374 \\
\hline Neutrophils $^{\mathrm{a}}$ & $3309 \pm 1378$ & $3328 \pm 1389$ & $3291 \pm 1384$ & 0.821 \\
\hline Lymphocytes $^{\mathrm{a}}$ & $1661 \pm 632$ & $1683 \pm 685$ & $1651 \pm 583$ & 0.754 \\
\hline Platelets ${ }^{\mathrm{a}}$ & $250 \pm 72$ & $267 \pm 77$ & $237 \pm 65$ & 0.016 \\
\hline $\mathrm{CRP}^{\mathrm{a}}$ & $0.39 \pm 0.92$ & $0.48 \pm 1.09$ & $0.29 \pm 0.67$ & 0.202 \\
\hline Albumina & $3.8 \pm 0.4$ & $3.75 \pm 0.48$ & $3.88 \pm 0.32$ & 0.051 \\
\hline $\mathrm{mGPS}^{\mathrm{b}}$ & & & & 0.041 \\
\hline 0 & 69 & 29 & 40 & \\
\hline 1 & 73 & 36 & 37 & \\
\hline 2 & 21 & 17 & 4 & \\
\hline $\mathrm{CRP} / \mathrm{Alb}$ ratio $^{\mathrm{b}}$ & & & & 0.046 \\
\hline$\geq 0.0375$ & 69 & 41 & 28 & \\
\hline$<0.0375$ & 94 & 41 & 53 & \\
\hline $\mathrm{PNI}^{\mathrm{b}}$ & & & & 0.836 \\
\hline$\geq 51.02$ & 28 & 15 & 13 & \\
\hline$<51.02$ & 125 & 67 & 58 & \\
\hline$N_{L R}^{b}$ & & & & 0.052 \\
\hline$\geq 3.211$ & 32 & 21 & 11 & \\
\hline$<3.211$ & 131 & 61 & 70 & \\
\hline $\mathrm{PLR}^{\mathrm{b}}$ & & & & 0.471 \\
\hline$\geq 111.3$ & 123 & 64 & 59 & \\
\hline$<111.3$ & 40 & 18 & 22 & \\
\hline
\end{tabular}

aData are presented as mean \pm standard deviation. b ${ }^{b}$ ata are presented as number of patients. WBCs, White blood cells; CRP, C-reactive protein; mGPS, modified Glasgow prognostic score; CRP/Alb ratio, C-reactive protein-to-albumin ratio; PNI, prognostic nutritional index, NLR, neutrophilto-lymphocyte ratio; PLR, platelet-to-lymphocyte ratio.

esophageal cancer are presented in Table IV. In the univariate analysis, RFS was significantly worse in patients with T2 or deeper tumor invasion, positive lymph node metastasis, a high CRP/Alb ratio, and a high NLR. The multivariate analysis revealed that a high $\mathrm{CRP} / \mathrm{Alb}$ ratio was an independent prognostic factor, together with positive lymph node metastasis.

\section{Discussion}

In this study, we investigated the relationship between sarcopenia and systemic inflammatory response. Results showed that sarcopenia is associated with systemic inflammatory response such as high CRP/Alb ratio, while the latter is an independent prognostic marker for RFS in patients with esophageal cancer.

Several studies have investigated the association of the presence of sarcopenia and the systemic inflammatory response in patients with various cancer type $(22,31,35,36)$. However, to the best of our knowledge, this is the first study to demonstrate the relationship between the preoperative CRP/Alb ratio and sarcopenia in esophageal cancer patients.

In the studied cohort of patients with thoracic esophageal cancer, sarcopenia was significantly correlated with the
Table III. Receiver operating characteristic analysis to determine the optimal cut-off value for the recurrent status of esophageal cancer in each inflammatory factor.

\begin{tabular}{lccc}
\hline Variable & Cut-off value & AUC & $p$-Value \\
\hline CRP/Alb ratio & 0.0375 & 0.642 & 0.013 \\
NLR & 3.211 & 0.566 & 0.006 \\
PNI & 51.02 & 0.526 & 0.416 \\
PLR & 111.3 & 0.553 & 0.053 \\
\hline
\end{tabular}

AUC, Area under the curve; CRP/Alb ratio, C-reactive protein-toalbumin ratio; NLR, neutrophil-to-lymphocyte ratio; PNI, prognostic nutritional index; PLR, platelet-to-lymphocyte ratio.

mGPS. This result is similar to that of a recent study by Richards et al., who demonstrated a significant association between low skeletal muscle index and elevated systemic inflammatory response, as measured by the mGPS in patients with primary operable colorectal cancer (35). Similarly, Kim et al. reported that the mGPS correlated with height-adjusted muscle mass, as calculated by CT imaging, in patients with small cell lung cancer (36). 

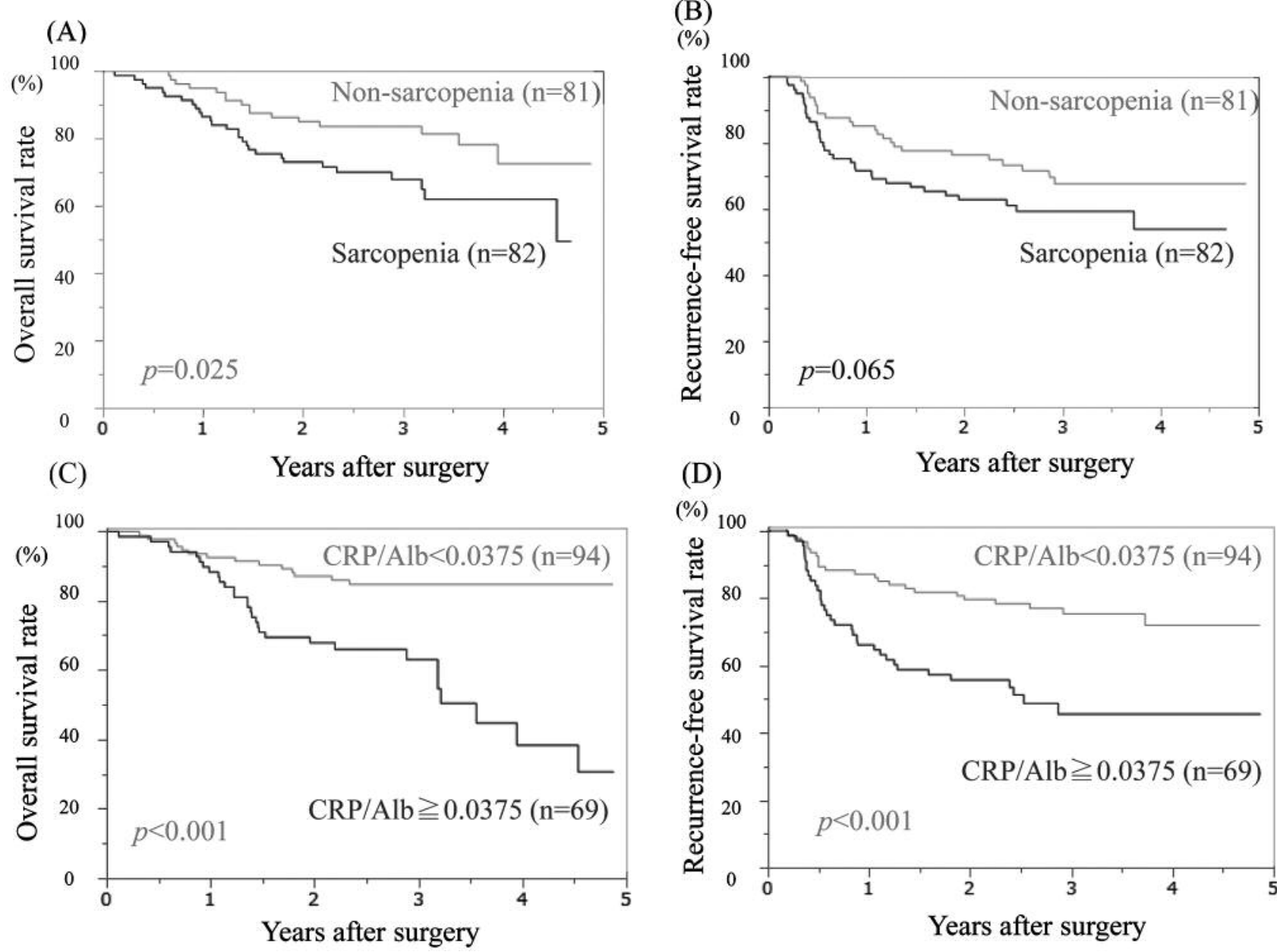

Figure 1. Overall survival $(A)$ and recurrence-free survival $(B)$ rates following esophagectomy in esophageal cancer patients with or without sarcopenia. Overall survival $(C)$ and recurrence-free survival $(D)$ rates following esophagectomy, in esophageal cancer patients with a low or a high C-reactive protein-to-albumin $(C R P / A l b)$ ratio.

Further analysis of the relationships between inflammatory markers and the survival rate revealed that CRP/Alb ratio, mGPS, and NLR had a significant impact on OS in the esophageal cancer patients. However, the multivariate analysis showed that only the CRP/Alb ratio was an independent prognostic factor for survival. This result is similar to that of a recent study by Xu et al., who showed that $\mathrm{CRP} / \mathrm{Alb}$ ratio is a prognostic factor in patients with primary operable esophageal squamous cell carcinoma (37). Specifically, they compared the mGPS, NLR, PLR, and $\mathrm{CRP} / \mathrm{Alb}$ ratio with established prognostic factors and found that the CRP/Alb ratio may be superior to other inflammation-based prognostic scores in terms of its prognostic ability. Furthermore, Haruki et al. compared the mGPS and CRP/Alb ratio with established prognostic factors in pancreatic cancer patients with pancreatic resection. This study reported that the $\mathrm{CRP} / \mathrm{Alb}$ ratio may be an independent and significant indicator of poor long-term outcomes in the studied population, and that it may be superior to the mGPS in terms of its prognostic ability (38). Kinoshita et al. also explored the prognostic value of the CRP/Alb ratio in patients with hepatocellular carcinoma (39). They found that it had comparable performance with the mGPS and better performance than the NLR, similar to the findings of the present study. These results suggest that the predictive value of the CRP/Alb ratio may be superior to that of the mGPS.

Sarcopenia has recently received great attention as a negative factor for long-term outcomes in patients with solid cancers (40-42). However, only a few studies have investigated the effect of sarcopenia on the prognosis of patients with esophageal cancer. Nakashima et al. retrospectively reviewed the surgical outcomes in 341 patients with esophageal cancer assigned to 2 age groups ( $<65$ and $>65$ years). They showed that the survival rate was 

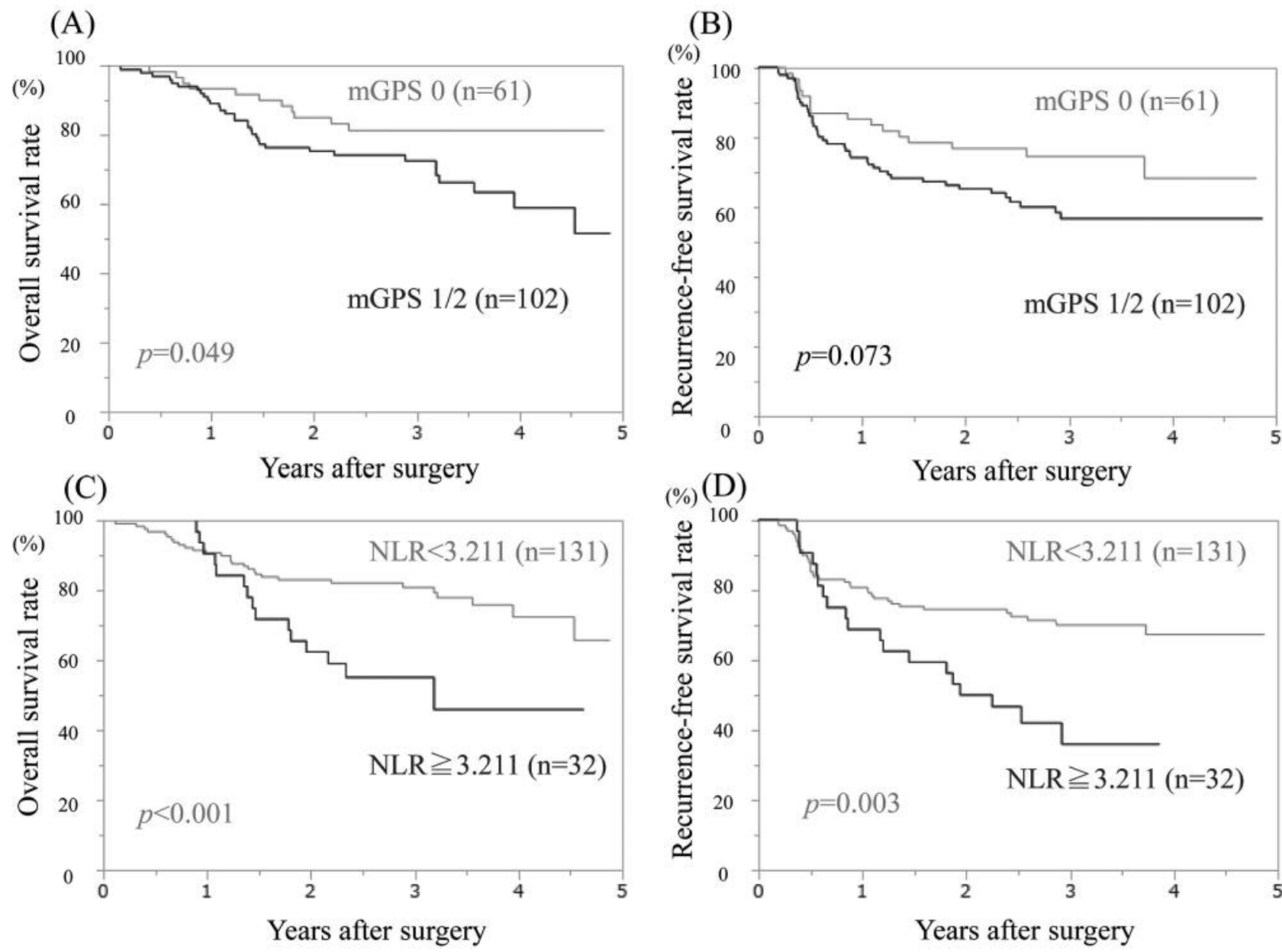

Figure 2. Overall survival (A) and recurrence-free survival (B) rates following esophagectomy, according to the modified Glasgow prognostic score $(m G P S)$, in patients with esophageal cancer. Overall survival $(C)$ and recurrence-free survival $(D)$ rates following esophagectomy, according to the neutrophil-to-lymphocyte ratio NLR), in patients with esophageal cancer.

significantly different between patients with and without sarcopenia in the older group (20). Elliot et al. retrospectively reviewed the surgical outcomes in 252 patients with locally advanced esophageal cancer who underwent neoadjuvant chemotherapy or chemoradiothreapy. They showed that sarcopenia increased during neoadjuvant therapy, and moreover it was associated with a higher risk of major postoperative complications, resulting in poor survival (43). These reports suggest that sarcopenia is a negative prognostic factor in patients with esophageal cancer. In the current study, the survival rate was significantly poorer in patients with than without sarcopenia, in accordance with these previous studies.

The reason for the poor prognosis in patients with concurrent cancer and sarcopenia has not been sufficiently elucidated. One potential explanation is that preoperative sarcopenia is related to the likelihood of postoperative complications $(21,43)$ leading to systemic inflammation and resulting in a poor prognosis (44). Indeed, many studies have shown that postoperative complications have a negative impact on the prognosis of patients $(45,46)$. However, in this study, no significant relationship between the presence of sarcopenia and the occurrence of postoperative complications was found. Another potential explanation is that sarcopenia may be associated with immunosuppression. Myokines, which are proteins secreted from skeletal muscles, have recently gained attention in anticancer research since they mediate exercise-induced metabolic improvement and antiinflammatory effects (47). In particular, specific myokines have been associated with anticancer immune function (47, 48). Thus, reduction of skeletal muscle may cause weakened immune function against cancer. Further research is needed to clarify the mechanism through which sarcopenia negatively 
(A)

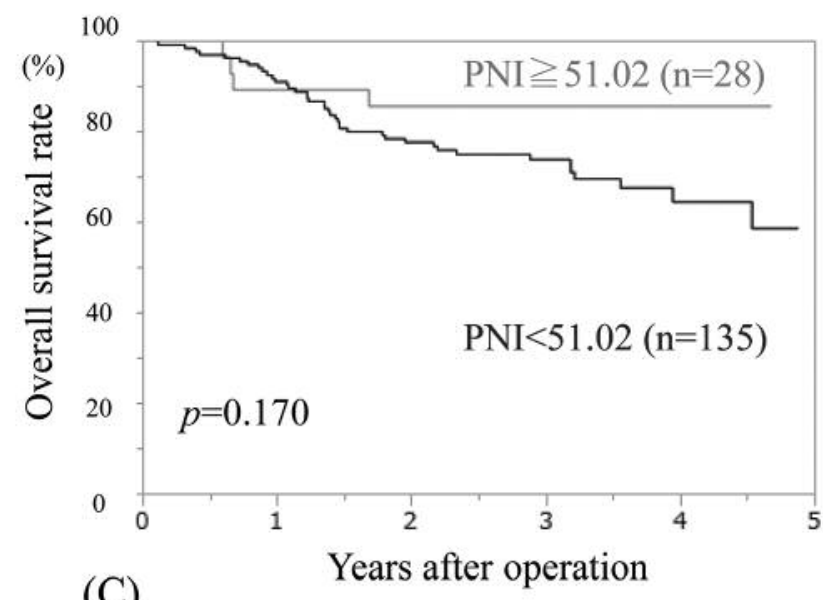

(C)

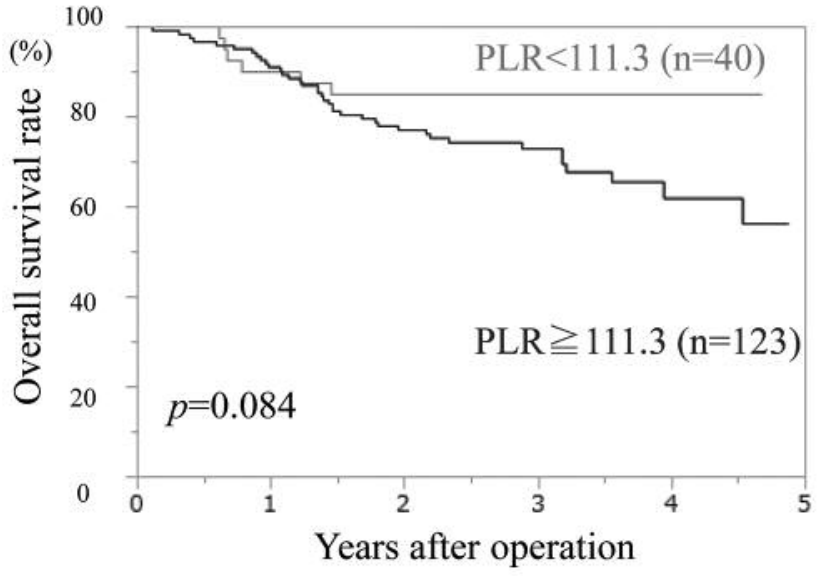

(B)

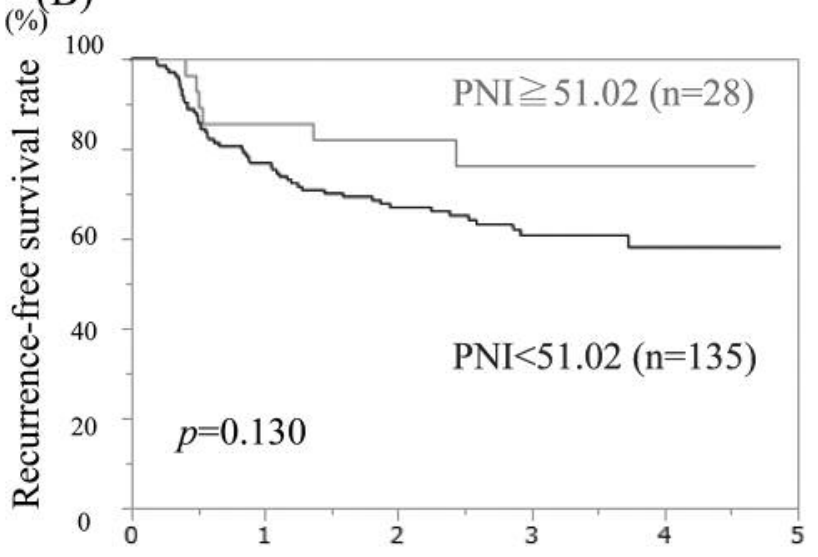

Years after operation

(\%) (D)

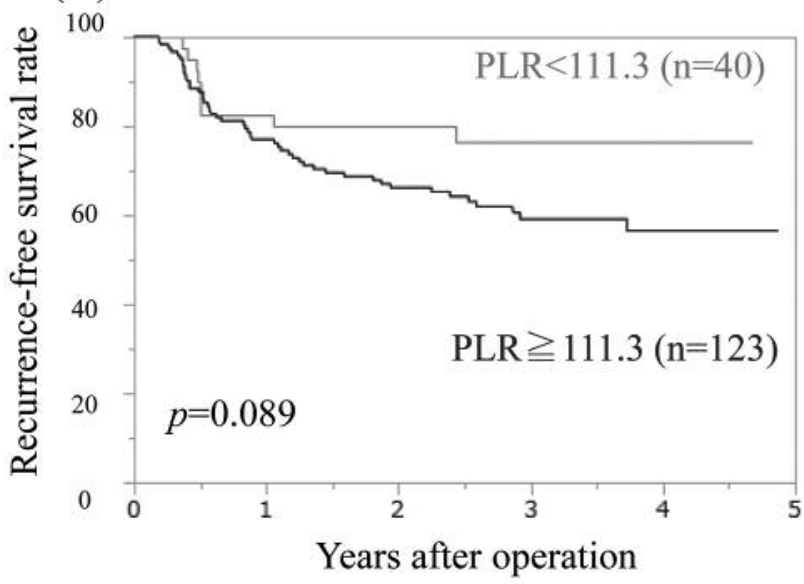

Figure 3. Overall survival (A) and recurrence-free survival (B) rates following esophagectomy, in patients with esophageal cancer stratified by the prognostic nutritional index $(P N I)$. Overall survival $(C)$ and recurrence-free survival $(D)$ following esophagectomy, in patients with esophageal cancer stratified by the platelet-to-lymphocyte ratio (PLR).

Table IV. Univariate and multivariate analyses of prognostic factors for recurrence-free survival in patients with esophageal cancer.

\begin{tabular}{|c|c|c|c|c|c|c|}
\hline & \multicolumn{3}{|c|}{ Univariate analysis } & \multicolumn{3}{|c|}{ Multivariate analysis } \\
\hline & Hazard ratio & $95 \% \mathrm{CI}$ & $p$-Value & Hazard ratio & $95 \% \mathrm{CI}$ & $p$-Value \\
\hline Age $(<70 v s . \geq 70$ years $)$ & 1.179 & $0.666-2.019$ & 0.561 & & & \\
\hline Gender (male vs. female) & 1.549 & $0.798-3.379$ & 0.206 & & & \\
\hline $\mathrm{pT}(0 / 1$ vs. 2/3/4) & 2.233 & $1.360-4.126$ & 0.002 & 1.282 & $0.691-2.450$ & 0.354 \\
\hline $\mathrm{pN}$ (absent vs. present) & 3.349 & $1.8550-6.479$ & $<0.001$ & 2.475 & $1.278-5.070$ & 0.006 \\
\hline Sarcopenia (absent $v s$. present) & 1.569 & $0.931-2.685$ & 0.065 & 1.240 & $0.715-2.170$ & 0.445 \\
\hline mGPS $(0 v s .1 / 2)$ & 1.693 & $0.969-3.107$ & 0.064 & 1.568 & $0.659-4.134$ & 0.318 \\
\hline $\mathrm{CRP} / \mathrm{Alb}$ ratio $(<0.00375$ vs. $\geq 0.00375)$ & 2.608 & $1.540-4.497$ & $<0.001$ & 2.462 & $1.128-6.179$ & 0.022 \\
\hline PNI $(<51.02 v s . \geq 51.02)$ & 1.181 & $0.691-1.991$ & 0.106 & & & \\
\hline $\operatorname{NLR}(<3.211 v s . \geq 3.211)$ & 2.280 & $1.285-3.913$ & 0.006 & 1.672 & $0.899-3.037$ & 0.102 \\
\hline $\operatorname{PLR}(<111 v s . \geq 111)$ & 1.836 & $0.947-4.002$ & 0.074 & 1.167 & $0.565-2.658$ & 0.688 \\
\hline
\end{tabular}

CI, Confidence interval; mGPS, modified Glasgow prognostic score; CRP/Alb ratio, C-reactive protein-to-albumin ratio; PNI, prognostic nutritional index; NLR, neutrophil-to-lymphocyte ratio; PLR, platelet-to-lymphocyte ratio. 
affects the prognosis of patients with cancer. Further research is needed to clarify the mechanism through which sarcopenia negatively affects the prognosis of patients with cancer.

This study has several limitations. First, we conducted this retrospective study in a single institution, and the number of patients was small. Second, information regarding proinflammatory cytokines such as TNF- $\alpha$, IL-1, and IL-6 was not obtained because of the retrospective design. Further in vitro and in vivo studies are needed to verify the relationship between SMM and proinflammatory cytokines in patients with esophageal cancer. Third, the median follow-up was relatively short because body composition before surgery was not assessed before January 2013. However, because recurrence mainly occurs within 2 years postoperatively $(49,50)$, the RFS rate was used to investigate independent prognostic factors.

In conclusion, sarcopenia is associated with systemic inflammatory response such as high $\mathrm{CRP} / \mathrm{Alb}$ ratio and mGPS, and high CRP/Alb ratio is an independent prognostic marker for RFS in patients with esophageal cancer. Modulating systemic inflammation may be a promising treatment for sarcopenia and potentially lead to improved prognosis of esophageal cancer patients.

\section{Conflicts of Interest}

All authors declare that they have no conflict of interest.

\section{Acknowledgements}

The Authors thank Angela Morben, DVM and ELS, from Edanz Group (www.edanzediting.com/ac), for editing a draft of this manuscript.

\section{References}

1 Enzinger PC and Mayer RJ: Esophageal cancer. N Engl J Med 349(23): 2241-2252, 2003.

2 Gertler R, Stein HJ, Langer R, Nettelmann M, Schuster T, Hoefler H, Siewert JR and Feith M: Long-term outcome of 2920 patients with cancers of the esophagus and esophagogastric junction: Evaluation of the new union internationale contre le cancer/american joint cancer committee staging system. Ann Surg 253(4): 689-698, 2011.

3 van Hagen P, Hulshof MC, van Lanschot JJ, Steyerberg EW, van Berge Henegouwen MI, Wijnhoven BP, Richel DJ, Nieuwenhuijzen GA, Hospers GA, Bonenkamp JJ, Cuesta MA, Blaisse RJ, Busch OR, ten Kate FJ, Creemers GJ, Punt CJ, Plukker JT, Verheul HM, Spillenaar Bilgen EJ, van Dekken H, van der Sangen MJ, Rozema T, Biermann K, Beukema JC, Piet $\mathrm{AH}$, van Rij CM, Reinders JG, Tilanus HW and van der Gaast A: Preoperative chemoradiotherapy for esophageal or junctional cancer. N Engl J Med 366(22): 2074-2084, 2012.

4 Miyata H, Yamasaki M, Miyazaki Y, Takahashi T, Kurokawa Y, Nakajima K, Takiguchi S, Mori M and Doki Y: Clinical importance of supraclavicular lymph node metastasis after neoadjuvant chemotherapy for esophageal squamous cell carcinoma. Ann Surg 262(2): 280-285, 2015.
5 Chen M, Huang J, Zhu Z, Zhang J and Li K: Systematic review and meta-analysis of tumor biomarkers in predicting prognosis in esophageal cancer. BMC Cancer 13: 539, 2013.

6 Omloo JM, van Heijl M, Hoekstra OS, van Berge Henegouwen MI, van Lanschot JJ and Sloof GW: Fdg-pet parameters as prognostic factor in esophageal cancer patients: A review. Ann Surg Oncol 18(12): 3338-3352, 2011.

7 Miyata H, Yamasaki M, Takahashi T, Murakami K, Tanaka K, Yukinori K, Nakajima K, Takiguchi S, Morii E, Hatazawa J, Mori M and Doki Y: Determinants of response to neoadjuvant chemotherapy for esophageal cancer using 18ffluorodeoxiglucose positron emission tomography (18f-fdg-pet). Ann Surg Oncol 21(2): 575-582, 2014.

8 Coussens LM and Werb Z: Inflammation and cancer. Nature 420(6917): 860-867, 2002.

9 Miyata H, Yamasaki M, Kurokawa Y, Takiguchi S, Nakajima K, Fujiwara Y, Mori $\mathrm{M}$ and Doki Y: Prognostic value of an inflammation-based score in patients undergoing pre-operative chemotherapy followed by surgery for esophageal cancer. Exp Ther Med 2(5): 879-885, 2011.

10 Kinoshita A, Onoda H, Imai N, Iwaku A, Oishi M, Fushiya N, Koike K, Nishino $\mathrm{H}$ and Tajiri $\mathrm{H}$ : Comparison of the prognostic value of inflammation-based prognostic scores in patients with hepatocellular carcinoma. Br J Cancer 107(6): 988-993, 2012.

11 Inoue D, Ozaka M, Matsuyama M, Yamada I, Takano K, Saiura A and Ishii H: Prognostic value of neutrophil-lymphocyte ratio and level of C-reactive protein in a large cohort of pancreatic cancer patients: A retrospective study in a single institute in japan. Jpn J Clin Oncol 45(1): 61-66, 2015.

12 Chen S, Yang X and Feng JF: A novel inflammation-based prognostic score for patients with esophageal squamous cell carcinoma: The c-reactive protein/prognostic nutritional index ratio. Oncotarget 7(38): 62123-62132, 2016.

13 Duan H, Zhang X, Wang FX, Cai MY, Ma GW, Yang H, Fu JH, Tan ZH, Meng YQ, Fu XY, Ma QL and Lin P: Prognostic role of neutrophil-lymphocyte ratio in operable esophageal squamous cell carcinoma. World J Gastroenterol 21(18): 55915597, 2015.

14 Xie X, Luo KJ, Hu Y, Wang JY and Chen J: Prognostic value of preoperative platelet-lymphocyte and neutrophil-lymphocyte ratio in patients undergoing surgery for esophageal squamous cell cancer. Dis Esophagus 29(1): 79-85, 2016.

15 Janssen I, Heymsfield SB and Ross R: Low relative skeletal muscle mass (sarcopenia) in older persons is associated with functional impairment and physical disability. J Am Geriatr Soc 50(5): 889-896, 2002.

16 Cruz-Jentoft AJ, Baeyens JP, Bauer JM, Boirie Y, Cederholm T, Landi F, Martin FC, Michel JP, Rolland Y, Schneider SM, Topinkova E, Vandewoude $M$ and Zamboni M: Sarcopenia: European consensus on definition and diagnosis: Report of the european working group on sarcopenia in older people. Age Ageing 39(4): 412-423, 2010.

17 Matsubara Y, Matsumoto T, Aoyagi Y, Tanaka S, Okadome J, Morisaki K, Shirabe K and Maehara Y: Sarcopenia is a prognostic factor for overall survival in patients with critical limb ischemia. J Vasc Surg 61(4): 945-950, 2015.

18 Sheetz KH, Zhao L, Holcombe SA, Wang SC, Reddy RM, Lin $\mathrm{J}$, Orringer MB and Chang AC: Decreased core muscle size is associated with worse patient survival following esophagectomy for cancer. Dis Esophagus 26(7): 716-722, 2013. 
19 Itoh S, Shirabe K, Matsumoto Y, Yoshiya S, Muto J, Harimoto N, Yamashita Y, Ikegami T, Yoshizumi T, Nishie A and Maehara Y: Effect of body composition on outcomes after hepatic resection for hepatocellular carcinoma. Ann Surg Oncol 21(9): 3063-3068, 2014

20 Nakashima Y, Saeki H, Nakanishi R, Sugiyama M, Kurashige J, Oki E and Maehara Y: Assessment of sarcopenia as a predictor of poor outcomes after esophagectomy in elderly patients with esophageal cancer. Ann Surg 267(6): 1100-1104, 2018.

21 Harada K, Ida S, Baba Y, Ishimoto T, Kosumi K, Tokunaga R, Izumi D, Ohuchi M, Nakamura K, Kiyozumi Y, Imamura Y, Iwatsuki M, Iwagami S, Miyamoto Y, Sakamoto Y, Yoshida N, Watanabe $\mathrm{M}$ and Baba $\mathrm{H}$ : Prognostic and clinical impact of sarcopenia in esophageal squamous cell carcinoma. Dis Esophagus 29(6): 627-633, 2016.

22 Feliciano EMC, Kroenke $\mathrm{CH}$, Meyerhardt JA, Prado CM, Bradshaw PT, Kwan ML, Xiao J, Alexeeff S, Corley D, Weltzien E, Castillo AL and Caan BJ: Association of systemic inflammation and sarcopenia with survival in nonmetastatic colorectal cancer: Results from the c scans study. JAMA Oncol 3(12): e172319, 2017.

23 Argiles JM, Busquets S and Lopez-Soriano FJ: The pivotal role of cytokines in muscle wasting during cancer. Int $\mathrm{J}$ Biochem Cell Biol 37(8): 1609-1619, 2005.

24 VanderVeen BN, Fix DK and Carson JA: Disrupted skeletal muscle mitochondrial dynamics, mitophagy, and biogenesis during cancer cachexia: A role for inflammation. Oxid Med Cell Longev 2017: 3292087, 2017.

25 Gupta D and Lis CG: Pretreatment serum albumin as a predictor of cancer survival: A systematic review of the epidemiological literature. Nutr J 9: 69, 2010.

26 Durham WJ, Dillon EL and Sheffield-Moore M: Inflammatory burden and amino acid metabolism in cancer cachexia. Curr Opin Clin Nutr Metab Care 12(1): 72-77, 2009

27 Muller MJ, Baracos V, Bosy-Westphal A, Dulloo AG, Eckel J, Fearon KC, Hall KD, Pietrobelli A, Sorensen TI, Speakman J, Trayhurn P, Visser $\mathrm{M}$ and Heymsfield SB: Functional body composition and related aspects in research on obesity and cachexia: Report on the 12th stock conference held on 6 and 7 september 2013 in hamburg, germany. Obes Rev 15(8): 640-656, 2014.

28 Wittekind C: [2010 tnm system: On the 7th edition of tnm classification of malignant tumors]. Pathologe 31(5): 331-332, 2010.

29 Fairclough E, Cairns E, Hamilton J and Kelly C: Evaluation of a modified early warning system for acute medical admissions and comparison with c-reactive protein/albumin ratio as a predictor of patient outcome. Clin Med (Lond) 9(1): 30-33, 2009.

30 Proctor MJ, Morrison DS, Talwar D, Balmer SM, Fletcher CD, O'Reilly DS, Foulis AK, Horgan PG and McMillan DC: A comparison of inflammation-based prognostic scores in patients with cancer. A Glasgow inflammation outcome study. Eur J Cancer 47(17): 2633-2641, 2011.

31 Liaw FY, Huang CF, Chen WL, Wu LW, Peng TC, Chang YW and Kao TW: Higher platelet-to-lymphocyte ratio increased the risk of sarcopenia in the community-dwelling older adults. Sci Rep 7(1): 16609, 2017.

32 Onodera T, Goseki N and Kosaki G: Prognostic nutritional index in gastrointestinal surgery of malnourished cancer patients. Nihon Geka Gakkai Zasshi 85(9): 1001-1005, 1984.
33 Kaido T, Ogawa K, Fujimoto Y, Ogura Y, Hata K, Ito T, Tomiyama K, Yagi S, Mori A and Uemoto S: Impact of sarcopenia on survival in patients undergoing living donor liver transplantation. Am J Transplant 13(6): 1549-1556, 2013.

34 Ida S, Watanabe M, Yoshida N, Baba Y, Umezaki N, Harada K, Karashima R, Imamura Y, Iwagami S and Baba H: Sarcopenia is a predictor of postoperative respiratory complications in patients with esophageal cancer. Ann Surg Oncol 22(13): 44324437, 2015.

35 Richards $\mathrm{CH}$, Roxburgh CS, MacMillan MT, Isswiasi S, Robertson EG, Guthrie GK, Horgan PG and McMillan DC: The relationships between body composition and the systemic inflammatory response in patients with primary operable colorectal cancer. PLoS One 7(8): e41883, 2012.

36 Kim EY, Kim YS, Seo JY, Park I, Ahn HK, Jeong YM, Kim JH and Kim N: The relationship between sarcopenia and systemic inflammatory response for cancer cachexia in small cell lung cancer. PLoS One 11(8): e0161125, 2016.

$37 \mathrm{Xu} \mathrm{XL}, \mathrm{Yu} \mathrm{HQ}, \mathrm{Hu}$ W, Song Q and Mao WM: A novel inflammation-based prognostic score, the c-reactive protein/ albumin ratio predicts the prognosis of patients with operable esophageal squamous cell carcinoma. PLoS One 10(9): e0138657, 2015.

38 Haruki K, Shiba H, Shirai Y, Horiuchi T, Iwase R, Fujiwara Y, Furukawa K, Misawa T and Yanaga K: The c-reactive protein to albumin ratio predicts long-term outcomes in patients with pancreatic cancer after pancreatic resection. World J Surg 40(9): 2254-2260, 2016.

39 Kinoshita A, Onoda H, Imai N, Iwaku A, Oishi M, Tanaka K, Fushiya N, Koike K, Nishino $\mathrm{H}$ and Matsushima M: The creactive protein/albumin ratio, a novel inflammation-based prognostic score, predicts outcomes in patients with hepatocellular carcinoma. Ann Surg Oncol 22(3): 803-810, 2015.

40 Voron T, Tselikas L, Pietrasz D, Pigneur F, Laurent A, Compagnon P, Salloum C, Luciani A and Azoulay D: Sarcopenia impacts on short- and long-term results of hepatectomy for hepatocellular carcinoma. Ann Surg 261(6): 1173-1183, 2015.

41 Miyamoto Y, Baba Y, Sakamoto Y, Ohuchi M, Tokunaga R, Kurashige J, Hiyoshi Y, Iwagami S, Yoshida N, Yoshida M, Watanabe $\mathrm{M}$ and Baba $\mathrm{H}$ : Sarcopenia is a negative prognostic factor after curative resection of colorectal cancer. Ann Surg Oncol 22(8): 2663-2668, 2015.

42 Shachar SS, Williams GR, Muss HB and Nishijima TF: Prognostic value of sarcopenia in adults with solid tumours: A meta-analysis and systematic review. Eur J Cancer 57: 58-67, 2016.

43 Elliott JA, Doyle SL, Murphy CF, King S, Guinan EM, Beddy P, Ravi N and Reynolds JV: Sarcopenia: Prevalence, and impact on operative and oncologic outcomes in the multimodal management of locally advanced esophageal cancer. Ann Surg 266(5): 822-830, 2017.

44 McSorley ST, Watt DG, Horgan PG and McMillan DC: Postoperative systemic inflammatory response, complication severity, and survival following surgery for colorectal cancer. Ann Surg Oncol 23(9): 2832-2840, 2016.

45 Booka E, Takeuchi H, Nishi T, Matsuda S, Kaburagi T, Fukuda K, Nakamura R, Takahashi T, Wada N, Kawakubo H, Omori T and Kitagawa Y: The impact of postoperative complications on survivals after esophagectomy for esophageal cancer. Medicine (Baltimore) 94(33): e1369, 2015. 
46 Kataoka K, Takeuchi H, Mizusawa J, Igaki H, Ozawa S, Abe T, Nakamura K, Kato K, Ando N and Kitagawa Y: Prognostic impact of postoperative morbidity after esophagectomy for esophageal cancer: Exploratory analysis of jcog9907. Ann Surg 265(6): 1152-1157, 2017.

47 Aoi W, Naito Y, Takagi T, Tanimura Y, Takanami Y, Kawai Y, Sakuma K, Hang LP, Mizushima K, Hirai Y, Koyama R, Wada S, Higashi A, Kokura S, Ichikawa H and Yoshikawa T: A novel myokine, secreted protein acidic and rich in cysteine (sparc), suppresses colon tumorigenesis via regular exercise. Gut 62(6): 882-889, 2013.

48 Roy P, Chowdhury S and Roy HK: Exercise-induced myokines as emerging therapeutic agents in colorectal cancer prevention and treatment. Future Oncol 14(4): 309-312, 2018.

49 Miyata H, Yamasaki M, Makino T, Miyazaki Y, Takahashi T, Kurokawa Y, Nakajima K, Takiguchi S, Mori M and Doki Y: Clinical outcome of esophagectomy in elderly patients with and without neoadjuvant therapy for thoracic esophageal cancer. Ann Surg Oncol 22(Suppl 3): S794-801, 2015.

50 Steffen T, Dietrich D, Schnider A, Kettelhack C, Huber O, Marti WR, Furrer M, Gloor B, Schiesser M, Thierstein S, Brauchli P and Ruhstaller T: Recurrence patterns and long-term results after induction chemotherapy, chemoradiotherapy, and curative surgery in patients with locally advanced esophageal cancer. Ann Surg, 2017. doi: 10.1097/SLA.0000000000002435. [Epub ahead of print].
Received November 20, 2018

Revised December 5, 2018

Accepted December 6, 2018 